\title{
The microbiology of ulcerative skin cancers: does the presence of pathogenic bacteria increase the risk of postoperative complications?
}

\author{
K Lutchminarian, 1 (D) DL Clarke ${ }^{2}$ (iD) \\ ${ }^{1}$ Department of Plastic and Reconstructive Surgery, Inkosi Albert Luthuli Hospital, University of KwaZulu-Natal, South Africa \\ ${ }^{2}$ Department of General Surgery, Greys Hospital, University of KwaZulu-Natal, South Africa
}

Corresponding author, email: heckate911@ymail.com

Background: To document the microbiology of ulcerative skin cancers, histological types, anatomical distribution and post-surgical complications among patients in KwaZulu-Natal and to determine whether a link exists between the presence of these bacteria and postoperative complications after resectional surgery and reconstruction.

Methods: One hundred swabs from ulcerative cancer wounds were collected from October 2015 to August 2017. The swabs were taken on admission according to swabbing protocol in the ward. Variables analysed were histology, anatomical site, microbiology, management and outcomes and patient specific risk factors - age, smoking, comorbidities and retroviral disease (RVD) status.

Results: Of the 100 skin cancer wounds, 87 cultured pathogenic bacteria: the majority were squamous cell carcinomas (SCC) (48\%); the remaining tumours were sarcomas (17\%), basal cell carcinomas (BCC) (14\%), melanomas (14\%) and other carcinomas (3\%). Among the bacteria cultured, Staphylococcus aureus was the most common pathogen found in $47 \%$ of the wounds, followed by Pseudomonas (25\%) and beta-haemolytic Streptococcus (15\%). The most virulent of pathogens: beta-haemolytic Streptococcus was most frequently found in melanomas.

Of the 74 wounds that underwent reconstruction, 24 had complications (wound sepsis, dehiscence, graft loss, flap sepsis). Although wound complications are multifactorial, it was observed that all 24 of the wounds that complicated cultured pathogenic bacteria (Staphylococcus aureus, Streptococcus and Pseudomonas). It was also found that there were 13 wounds that did not culture any pathogenic bacteria; these showed no complications on follow-up.

Conclusion: Although complications post-reconstruction of these lesions are multifactorial, the data from this study shows that pathogenic bacteria may play a role in increasing the post-surgical complication risk.

\section{Introduction}

Ulcerative skin cancers are morbid pathologies that require local excision and reconstruction. There are a number of different cancers which present as an ulcerating skin lesion and these can develop on different anatomical regions. ${ }^{1-3}$ The objective of reconstruction is providing tissue cover whilst preserving both function and aesthetics. A number of different reconstructive strategies and techniques can be used depending on the site and extent of the ulcerative lesion. ${ }^{4}$ Failed reconstruction can be devastating and has a multifactorial aetiology. This merits further study as strategies need to be developed to prevent or reduce the incidence of reconstructive failure. This audit reviews our experience with the management of these diverse lesions and attempts to identify factors implicated in failure of reconstruction. One of the factors which this study focuses on is the presence of preoperative microbiological contamination of the lesion and it attempts to document the common microbes found at different anatomical sites in each histopathological type of ulcerative skin cancer. The aim of the study is to determine if a link exists between the bacteria found in these wounds and complication rates after excision and reconstruction.

\section{Patients and methods}

\section{Selection process}

All patients presenting to the Plastic and Reconstructive Surgery service of the University of KwaZulu-Natal at Inkosi Albert Luthuli Central Hospital (IALCH) in Durban from October 2015 till August 2017 with an ulcerating cutaneous lesion were enrolled. Basic demographic data were recorded and the histological diagnosis, anatomical site and operative approach to each lesion were noted. Only patients with primary lesions which had not previously been operated on or received radiotherapy were eligible for inclusion. Prior to surgery, all lesions were swabbed according to a standard protocol and the swabs collected were sent for 


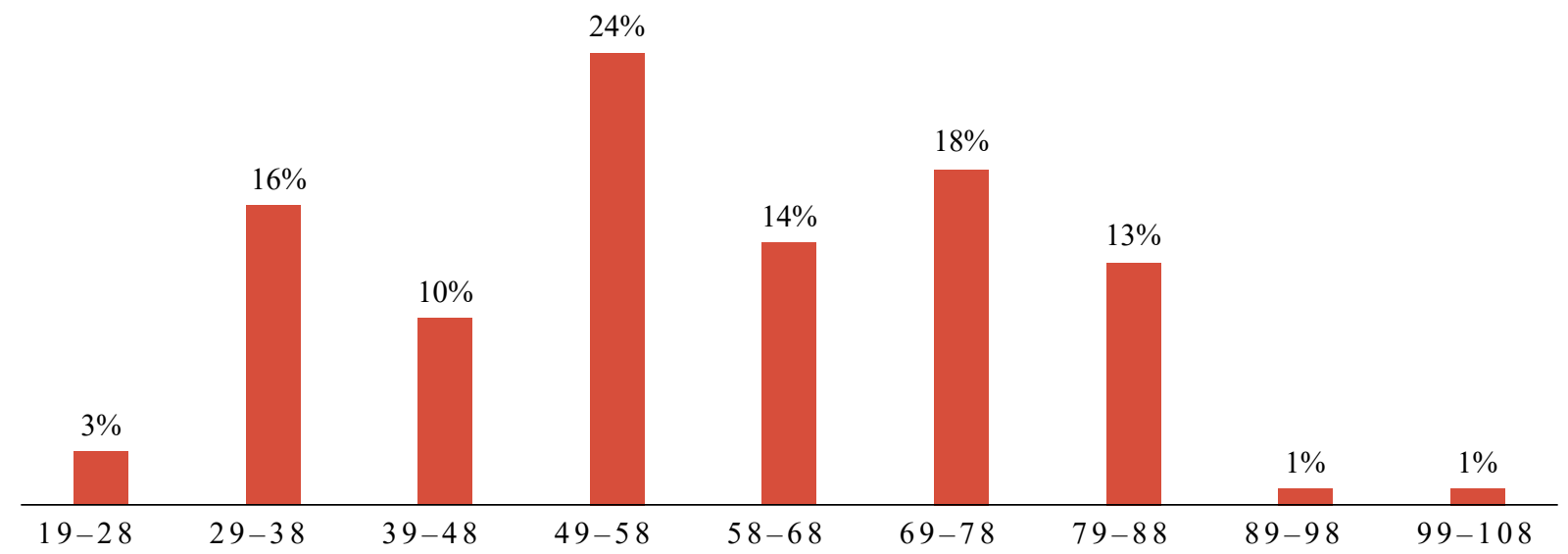

Figure 1: Age distribution of patients

microscopy, culture and sensitivity at the National Health Laboratory Services (NHLS) Microbiology lab, at IALCH. After excision, all specimens were labelled, then sent for histological analysis at the NHLS Histopathology laboratory.

\section{Age}

The study comprised of 100 patients. The age distribution is shown in Figure 1 and the majority (95\%) of patients were in the 30-90-year age group, with a mean age of 58 .

\section{Gender}

There were fifty males and fifty females in the group, providing a 1:1 ratio.

\section{Physical location}

The patients all lived in KwaZulu-Natal and had been referred from surrounding hospitals and clinics to the Department of Plastic Surgery at IALCH.

\section{Comorbidities}

The majority of these patients (67) were HIV negative, whilst 18 were HIV positive, and in 15 patients the HIV status was unknown. There were 28 smokers and five patients with albinism. The following comorbidities were noted hypertension (21), diabetes mellitus (6), cardiac dis-

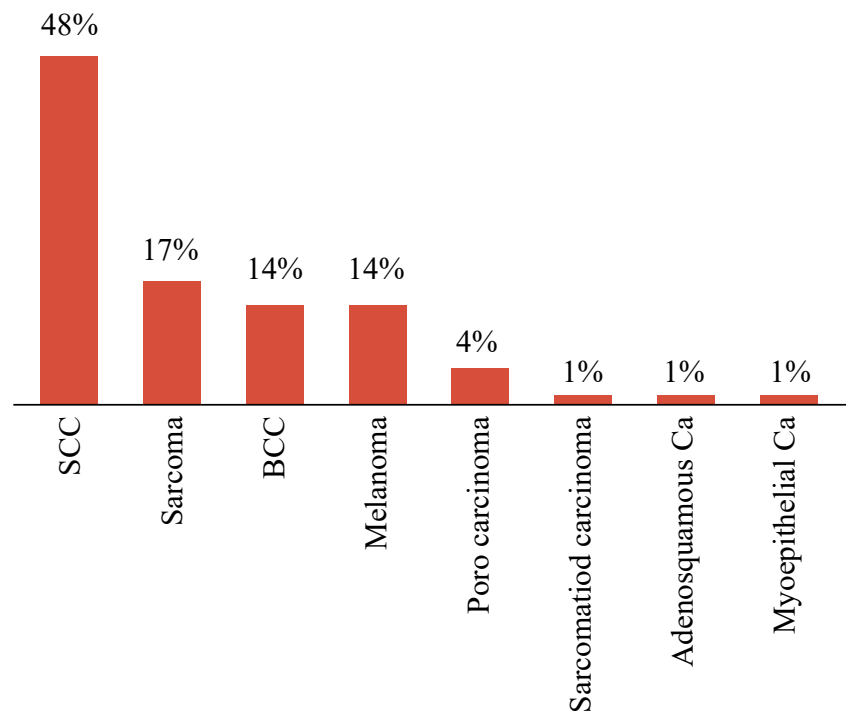

Figure 2: Percentage of each histologic type of cancer ease (5), obstructive lung diseases (4), neurological disease (3), endocrine disorders (2), psychiatric disorders (2) and peripheral vascular disease (1).

\section{Follow-up procedure}

The follow-up procedure involved outpatient clinic followup visits.

\section{Types of skin cancers}

As depicted in Figure 2, the cancers included all those ulcerating through the skin. The histological diagnosis in this study were: squamous cell carcinoma (48), sarcomas (17), basal cell carcinomas (14), and melanomas (14). There was a single case of sarcomatoid carcinoma, adenosquamous carcinoma and myoepithelial carcinoma.

\section{Site of skin cancers}

The anatomical distribution was head and neck area (52\%), which comprised of $38 \%$ on the face. These were further sub-divided into cheek (16), lip (8), ear (6), eyelids (4), forehead (2), nose (2) and the scalp (14). There were 28 lesions on the lower extremities of which 20 occurred on the foot and eight on the lower leg. There were seven lesions on the upper limb, four in the groin, four on the back, three on the buttock and two on the chest.

\section{Microbiology}

Among the bacteria cultured, Staphylococcus aureus was the most common pathogen found in 45 of the wounds, followed by Pseudomonas aeruginosa (25) and betahaemolytic Streptococcus (16): Streptococcus pyogenes (5), Streptococcus anginosus (2), Group A Streptococcus (3), Group C Streptococcus (1), Group G Streptococcus (5). The remaining microbes comprised of Enterococcus faecalis (5), E. coli (3), Enterobacter cloacae (2), Enterococcus gallinarum (1), Klebsiella pneumoniae (3), Klebsiella oxytoca (1), Morganella morganii (3), and Serratia marcescens (3).

The microbiology showed that $30 \%$ of the wounds (21 wounds) cultured more than one organism. The most common combination was Staphylococcus aureus with either Pseudomonas aeruginosa and/or betahaemolytic Streptococcus (13 wounds). Two wounds had cultured Pseudomonas aeruginosa and beta-haemolytic Streptococcus. Four wounds found enterobacteriaceae 


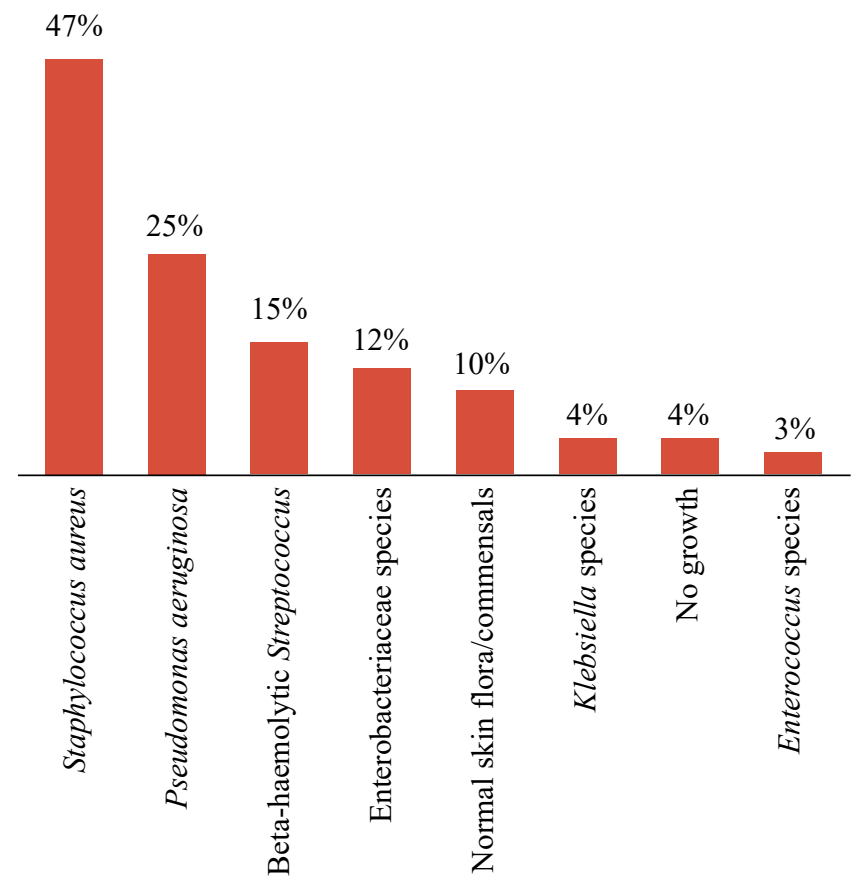

Figure 3: Microbiology: culture of the ulcerative skin lesions as a percentage of the total sample

species occurring with either Pseudomonas aeruginosa or Klebsiella species.

Non-pathogenic bacteria were found in $9 \%$ of the wounds: 11 wounds had normal skin flora/commensals and three of the wounds were reported as "no growth" on culture; on further consultation with the Microbiology department at IALCH - this simply meant that there was "no pathogenic bacterial growth" identified and thus also included nonpathogenic bacteria, not causing harm to the tissue. Hence, for the simplicity of this study, no growth and skin commensals were grouped into one category.

The upper limb had $7 \%$ of the lesions and the most common bacteria found here was Staphylococcus aureus. The remaining lesions were located in the groin (4\%) where the most common pathogen was Enterococcus, the back (4\%) where the most common bacteria found was Pseudomonas aeruginosa, the buttock (3\%) commonly cultured multiple organisms: Staphylococcus aureus, Serratia species and Klebsiella. The $2 \%$ of chest lesions cultured Pseudomonas.

As depicted in the above, it is seen that Staphylococcus aureus is the most common pathogen in the head and neck and upper and lower limbs. The areas that were covered and conducive to a warm, moist environment, such as chest, back and foot, found Pseudomonas as the most commonly cultured organism. Multiple organisms were cultured in the foot, including Staphylococcus and Pseudomonas, and this area also showed an affinity for culturing beta-haemolytic Streptococcus. The groin mostly cultured gram-positive facultative anaerobes, the Enterococcus species. The other area where multiple pathogens were commonly found was the buttock, where Staphylococcus aureus and the gramnegatives from the Enterobacteriaceae family, both Serratia species and Klebsiella, predominated. The majority of the Staphylococcus aureus was cultured in SCC wounds (47\%), $23 \%$ was found in BCCs and 14\% in sarcomas; $63 \%$ of Pseudomonas aeruginosa was found in SCC wounds.
The most common pathogenic bacteria found in each cancer were as shown in Table I.

\begin{tabular}{|c|c|}
\hline Skin cancer & Bacteria \\
\hline $\mathrm{SCC}$ & $\begin{array}{l}\text { Staphylococcus aureus - } 39 \% \\
\beta \text {-haemolytic Streptococcus - } 17 \% \\
\text { Pseudomonas aeruginosa }-29 \%\end{array}$ \\
\hline Sarcoma & $\begin{array}{l}\text { Staphylococcus aureus - 33\% } \\
\beta \text {-haemolytic Streptococcus - 17\% } \\
\text { Pseudomonas aeruginosa }-17 \%\end{array}$ \\
\hline $\mathrm{BCC}$ & Staphylococcus aureus - $100 \%$ \\
\hline Melanoma & $\begin{array}{l}\text { Staphylococcus aureus }-21 \% \\
\beta \text {-haemolytic Streptococcus }-29 \% \\
\text { Pseudomonas aeruginosa }-21 \%\end{array}$ \\
\hline
\end{tabular}

SCC, sarcoma and melanoma ulcers have shown a tendency to culture more than one pathogenic bacteria, whilst BCC ulcers display only Staphylococcus aureus.

The antibiotic sensitivity of each pathogen to different antibiotics was also recorded and analysed. Ninety-six per cent of Staphylococcus aureus was found to be sensitive to cloxacillin. Four percent of Staphylococcus aureus was methicillin-resistant (MRSA) and sensitive to vancomycin. All Pseudomonas aeruginosa cultured were sensitive to ciprofloxacin. The beta-haemolytic streptococci group were all sensitive to penicillin.

\section{Management}

Twenty-six patients were managed non-surgically, with either palliative chemotherapy or radiotherapy. Seventy-four patients underwent excision and thereafter reconstruction. The reconstructive approaches included simple primary closure (9), skin grafts (29) and local flaps (17), regional flaps (11) and free flaps (11).

\section{Complications}

Of the 74 patients undergoing excision, 24 (32\%) experienced a wound related complication. These included graft loss (7) and wound dehiscence (7), chronic wound/sinus (1), failed flap (1), partial flap loss (1) and wound sepsis (1).

Of the 74 wounds that were operated on, 24 wounds had complications and the most common complication was graft loss.

As illustrated in Table II, multiple organisms were found in two of the seven wounds associated with graft loss.

Five of the seven graft losses were associated with Staphylococcus aureus and three of seven graft losses were associated with $\beta$-haemolytic streptococci. Two out of seven losses were associated with Pseudomonas aeruginosa. It was also an important finding that although not every graft loss had streptococci, every wound that had streptococci had graft loss.

Patient risk factors were also analysed, and the most significant risk factors were diabetes mellitus and RVD reactive patients. Graft loss was found in $33 \%$ of diabetics and in $11 \%$ of this risk group.

Multiple pathogenic organisms were cultured in 17 patients who were operated on and complications arose in seven of them: three failed flaps, two graft losses, one wound dehiscence, and one chronic wound. 


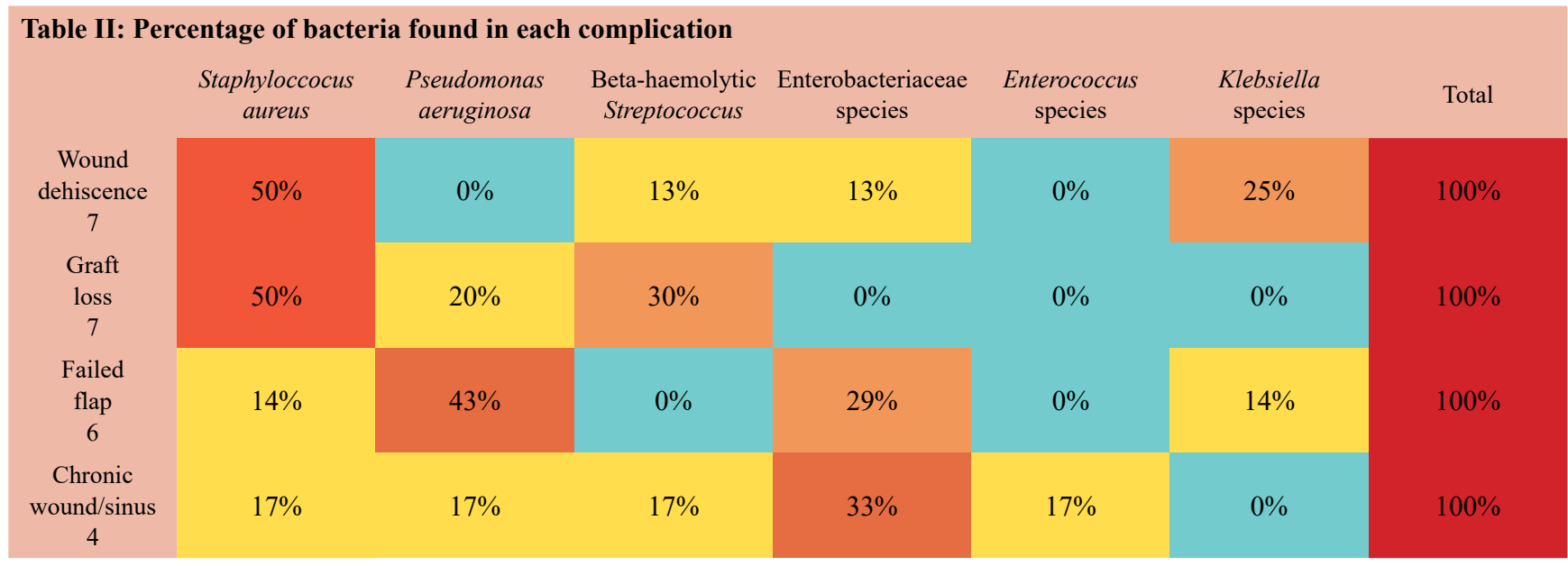

Fifty of the 74 wounds did not have complications (13 non pathogens, 37 pathogens), all 24 wounds that complicated had cultured pathogenic bacteria.

Another important finding was that all 13 of the "clean wounds" that cultured no pathogens, had no complications postoperatively.

\section{Discussion}

All open skin wounds are colonised with bacteria, but they are not always infected. ${ }^{5}$ Also, inflammation occurs in all wounds during healing, whether they are infected or not. Staphylococcus aureus is the most frequently isolated bacterial pathogen in wounds; it is the organism type rather than the amount of bacteria present that has the greater effect on wound healing. Aerobic or facultative pathogens, i.e. $S$. aureus, P. aeruginosa and beta-haemolytic Streptococcus are the primary causes of delayed wound healing and infection. ${ }^{5}$

If skin is broken, its protective mechanisms are impaired and the environment favours bacterial growth. Chronic wounds can degenerate into malignancy. ${ }^{5}$ About $3 \%$ of cancers are mistaken for chronic wounds. Advanced cancers appear as ulcerative wounds, because they outgrow their blood supply and erode. ${ }^{5}$

In France, at the University of Cergy Pontoise, a 42-day study was done to investigate the presence of bacterial floras (aerobes, aero-anaerobes, and anaerobes) and detect the presence of biofilms on 40 malignant wounds associated with breast cancer. Biofilms were found on 32 malignant wounds and bacterial floras in 25 malignant wounds. A mixed group of flora were identified and anaerobic bacteria were found in $70 \%$ of the wounds. The study showed that the bacterial flora of tumour wounds is different to those in stable chronic wounds. By the time symptoms develop, the number and the type of bacterial species as well as the total bacterial load have already created a micro-biological imbalance. This suggests that treating the bacteria organised in biofilms could be effective before the emergence of symptoms. ${ }^{6}$

Knowledge of the bacteriology of ulcerative tumours and treatment of these wounds with appropriate antibiotics may be beneficial. ${ }^{7}$

The bacteriology of skin cancer lesions may be important and bacteria can be identified in a number of types of skin cancers. ${ }^{8}$ Larger numbers of bacteria can be seen in the areas of cancer than in other non-cancerous parts of the wound. ${ }^{9}$ These microbes can be identified in "pre-cancerous" conditions, and when the cancer is "cured", the microbe can still be found in the damaged, previously cancerous areas. There is a propensity for microbes to still be present in the wound bed even after complete excision of the tumour and thus contribute to the risk of postoperative complications. This is especially a concern in an immunocompromised patient.

Appropriate administration of culture-directed antibiotics, changing of gloves and instruments, and irrigation of the wound bed with antibacterial wash after excision could therefore be considered beneficial.

As recommended by the South African Antibiotic Stewardship Programme (SAASP),${ }^{10}$ when an antibiotic is indicated, it must be the right choice at the right dose. The correct dosing interval, route of administration and duration of treatment should be adhered to. Further recommendations include the use first-line antibiotics for the common bacteria found in wounds. With the exception of multi-drug resistant organisms, Staphylococcus species are sensitive to coamoxiclav or clindamycin, and Streptococcus is sensitive to amoxicillin or co-amoxiclav. Pseudomonas is sensitive to ciprofloxacin or aminoglycosides. The role of prophylactic antibiotics in ulcerative skin tumours is yet to be determined.

The data in this study shows that pathogenic bacteria may play a role in increasing the post-surgical complication risk, i.e. flap sepsis, skin graft loss, and chronic non-healing wounds.

\section{Limitations}

There were a few limitations to this study. This was a single centre review, and there was no comparison group. The implementation of a wound swabbing protocol was complicated by variations in swabbing technique and wound characteristics. Finally, wound complications are multifactorial, even though common patient risk factors for wound complications were analysed (RVD status, diabetes, smoking, age). Although this study aimed to determine whether microbiology should be factored into the perioperative management of tumour extirpative and reconstructive surgery, there are other extrinsic and intrinsic patient and wound factors which also impact on outcome.

\section{Conclusion and recommendations}

This study provides an overview of common bacteria cultured in ulcerative skin cancers. Although complications post-reconstruction are multifactorial, the data from this study shows that pathogenic bacteria may play a role in 
increasing the post-surgical complication risk. Therefore, further studies in multiple centres are warranted.

\section{Conflict of interest}

The authors declare no conflict of interest.

\section{Funding source}

None.

\section{Ethical approval}

Ethics approval was obtained from the University of KwaZulu-Natal Biomedical Research Ethics committee, BE015-17.

\section{ORCID}

K Lutchminarian (iD https://orcid.org/0000-0001-5198-1994

DL Clarke (iD https://orcid.org/0000-0002-6954-153X

\section{REFERENCES}

1. Rippey JJ, Rippey E. Epidemiology of malignant melanoma of the skin in South Africa. S Afr Med J. 1984;65:595-8.

2. Shaw JHF, Koea JB. Acral (volar-subungual) melanoma in Auckland, New Zealand. Br J Surg. 1988;75:69-72.
3. Rippey JJ, Rippey E, Giraud RMA. Pathology of malignant melanoma of the skin in black Africans. S Afr Med J. 1975;49:789-92.

4. Gervasoni JE, Tanefa C, Chung MA, Cady B. Biologic and clinical significance of lymphadenectomy. Surg Clin North Am. 2000;80;1631-73.

5. Nicks B, Ayello E, Woo K, et al. Acute wound management: revisiting the approach to assessment, irrigation, and closure considerations. Int J Emerg Med. 2010;3(4):399-407.

6. Fromantin I, Seyer D, Watson S, et al. Bacterial floras and biofilms of malignant wounds associated with breast cancers. JCM. 2013;51(10):3368-71.

7. Hoste E, Arwert E, Lal R, et al. Innate sensing of microbial products promotes wound-induced skin cancer. Nat Commun. 2015;6:5932.

8. LeBlanc DM, Ramanadham SR, Wells DD. Basal cell carcinoma, squamous cell carcinoma and melanoma. In: Janis JE, editor. Essentials of Plastic Surgery. 2nd ed. New York: Thieme Medical Publishers, Inc.; 2017. p. 176-94.

9. Hooper S, Wilson M, Crean S, Myers JN, Jeffrey N. Exploring the link between microorganisms and oral cancer: a systematic review of the literature. Head Neck. 2009;31(9):1228-39.

10. Wasserman S, Boyles T, Mendelson M. A pocket guide to antibiotic prescribing for adults in South Africa 2015. 2nd ed. South Africa: Sean Wasserman; 2015. 